\title{
Differential neurotoxic effects of in utero and lactational exposure to hydroxylated polychlorinated biphenyl (OH-PCB 106) on spontaneous locomotor activity and motor coordination in young adult male mice
}

\author{
Asahi Haijima ${ }^{1,2}$, Ronny Lesmana2,3, Noriaki Shimokawa',4, Izuki Amano², \\ Yusuke Takatsuru² and Noriyuki Koibuchi² \\ ${ }^{1}$ Center for Medical Education, Gunma University Graduate School of Medicine, \\ 3-39-22 Showa-machi, Maebashi, Gunma 371-8511, Japan \\ ${ }^{2}$ Department of Integrative Physiology, Gunma University Graduate School of Medicine, \\ 3-39-22 Showa-machi, Maebashi, Gunma 371-8511, Japan \\ ${ }^{3}$ Department of Physiology, Universitas Padjadjaran, Bandung 45363, Indonesia \\ ${ }^{4}$ Department of Nutrition, Takasaki University of Health and Welfare, 37-1 \\ Nakaoorui-machi, Takasaki, Gunma 370-0033, Japan
}

(Received September 12, 2016; Accepted April 1, 2017)

\begin{abstract}
We investigated whether in utero or lactational exposure to 4-hydroxy-2',3,3',4',5'-pentachlorobiphenyl (OH-PCB 106) affects spontaneous locomotor activity and motor coordination in young adult male mice. For in utero exposure, pregnant C57BL/6J mice received 0.05 or $0.5 \mathrm{mg} / \mathrm{kg}$ body weight of OH-PCB 106 or corn oil vehicle via gavage every second day from gestational day 10 to 18 . For lactational exposure, the different groups of dams received $0.05 \mathrm{or} 0.5 \mathrm{mg} / \mathrm{kg}$ body weight of OH-PCB 106 or corn oil vehicle via gavage every second day from postpartum day 3 to 13. At 6-7 weeks of age, the spontaneous locomotor activities of male offspring were evaluated for a 24 -hr continuous session in a home cage and in an open field for 30-min. Motor coordination function on an accelerating rotarod was also measured. Mice exposed prenatally to OH-PCB 106 showed increased spontaneous locomotor activities during the dark phase in the home cage and during the first 10-min in the open field compared with control mice. Mice exposed lactationally to OH-PCB 106, however, did not show a time-dependent decrease in locomotor activity in the open field. Instead, their locomotor activity increased significantly during the second 10-min block. In addition, mice exposed lactationally to OH-PCB 106 displayed impairments in motor coordination in the rotarod test. These results suggest that perinatal exposure to OH-PCB 106 affects motor behaviors in young adult male mice. Depending on the period of exposure, OH-PCB 106 may have different effects on neurobehavioral development.
\end{abstract}

Key words: Hydroxylated polychlorinated biphenyl, Developmental neurotoxicity, Locomotor activity, Open field, Rotarod, Mouse

\section{INTRODUCTION}

Polychlorinated biphenyls (PCBs) are a group of persistent organic pollutants that are ubiquitously present in the environment (Breivik et al., 2002; Tehrani and Van Aken, 2014; Winneke et al., 2002). PCBs bioaccumulate through the food chain. Although the production of PCBs was banned in 1970s, they have been detected in samples of human blood and tissues (Donato et al., 2006; Koopman-Esseboom et al., 1994; Pinto et al., 2008) because of their chemical stability and high lipophilicity. PCB congeners are endocrine disruptors that can cause adverse effects on reproductive, immune, and neurological systems in humans (Carpenter, 1998; Swanson et al., 1995). In addition, epidemiological and animal studies have suggested that perinatal exposure to PCBs

Correspondence: Asahi Haijima (E-mail: alps@gunma-u.ac.jp) 
affects the development of brain functions in offspring even when exposure level is too low to affect mothers (Cocchi et al., 2009; Schantz et al., 1997, 2003; Stewart et al., 2000; Winneke, 2011). Perinatal exposure to PCBs and other environmental chemicals have been considered risk factors for developmental disabilities including learning disorders, attention-deficit hyperactivity disorder and autism, the prevalence of which has increased in recent years (Eubig et al., 2010; Kuroda, 2003; Winneke, 2011). Thus, the developmental neurotoxicity of PCBs is a serious public health concern.

In addition to $\mathrm{PCB}$ congeners, their metabolites, hydroxylated PCBs (OH-PCBs), are also suspected to have endocrine-disrupting and neurotoxic effects because their chemical structures are similar to those of the thyroid hormone (TH) (Kimura-Kuroda et al., 2007; Quinete et al., 2014). In addition, OH-PCBs can be transferred to the fetus/neonate via the placenta and lactation (Fängström et al., 2002; Lesmana et al., 2014; Meerts et al., 2002; Park et al., 2008; Sandau et al., 2002; Sinjari and Darnerud, 1998; Soechitram et al., 2004). In previous in vitro studies, our group and others have reported that exposure to 4-hydroxy-2',3,3',4',5'-pentachlorobiphenyl (OH-PCB 106), which is one of the OH-PCBs, may affect TH function (Amano et al., 2010; Ghisari and Bonefeld-Jorgensen, 2005; Iwasaki et al., 2002; KimuraKuroda et al., 2007; Miyazaki et al., 2004, 2008), important for brain development (Gilbert et al., 2012; Koibuchi and Chin, 2000; Koibuchi, 2013). In addition, exposure to OH-PCB 106 suppressed the TH-dependent dendritic development of cultured cerebellar Purkinje cells (Kimura-Kuroda et al., 2007), and affected intracellular $\mathrm{Ca}^{2+}$ oscillation in cultured cerebral neurons (Londoño et al., 2010). Intracellular $\mathrm{Ca}^{2+}$ plays important roles in various neurodevelopmental processes including cell proliferation, differentiation, dendritic spine growth, synaptic plasticity and neurotransmission (Berridge et al., 2000; Ciccolini et al., 2003). These studies suggest that perinatal OH-PCB 106 exposure may affect neurobehavioral development through multiple pathways. However, the in vivo neurotoxic effects of OH-PCB 106 have scarcely been investigated in mouse offspring. To understand the impact of OH-PCB 106 neurotoxicity, it is important to clarify how perinatal exposure affects behavioral traits. Previous human and rat studies have suggested that perinatal exposure to some PCB congeners may induce hyperactivity and motor abnormalities (Berger et al., 2001; Berghuis et al., 2013; Boix et al., 2010; Kuriyama and Chahoud, 2004; Lombardo et al., 2015; Roegge and Schantz, 2006). In addition, lactational exposure to $\mathrm{OH}-$ PCB 106 induced hyperactivity in male rat offspring
(Lesmana et al., 2014), Furthermore, OH-PCB 106 treatment inhibited the dendritic development of cultured cerebellar Purkinje cells (Kimura-Kuroda et al., 2005, 2007), which play an important role in motor coodination. Based on these findings, we focused on the neurotoxic effects of OH-PCB 106 exposure on the motor behaviors.

The aim of this study was to investigate the effects of perinatal exposure to OH-PCB 106 on spontaneous locomotor activity in the home cage and novel environments, as well as on motor coordination in young adult male mice. Since exposure to OH-PCB 106 in rats affects locomotor activities in male but not female offspring (Lesmana et al., 2014), only male offspring were used in this study. Neuronal differentiation and neural circuit formation are regulated in a temporal and spatial-specific manner, so the neurotoxic effects of $\mathrm{OH}-\mathrm{PCB} 106$ exposure may differ depending on degree of exposure during the perinatal period. We therefore examined the differential neurotoxicity of in utero and lactational exposure to OH-PCB 106.

\section{MATERIALS AND METHODS}

\section{Chemical}

OH-PCB 106 (CAS No. 67651-35-8) was purchased from AccuStandard Chemicals (HPCB-5005S, purity $99 \%$, New Haven, CT, USA). It was dissolved in pure corn oil, which did not affect dam's body weight during pregnancy and lactational period, and pup's body weight at postnatal day (P) 7, 14, 21 and 42 at the concentrations used in this study (Supplemental Fig. S1).

\section{Animals and exposure to chemicals}

The animal experimentation protocol used for this study was approved by the Animal Care and Experimentation Committee, Gunma University Showa Campus. Time-mated pregnant C57BL/6J mice at gestational day (GD) 8 were obtained from Japan SLC (Shizuoka, Japan). The day of the presence of a sperm plug was defined as GD 0, and the day of delivery was designated as $\mathrm{P} 0$. They were housed in a temperature- and humiditycontrolled room $\left(22-24^{\circ} \mathrm{C}, 30-60 \%\right.$ humidity), and were maintained on a 12-hr light/dark cycle (lights on between 07:00 and 19:00). A commercial rodent diet (MF, Oriental Yeast, Tokyo, Japan) and water were provided ad libitum. The pregnant mice were randomly assigned to six groups: for in utero exposure, pregnant mice received 0.05 or $0.5 \mathrm{mg} / \mathrm{kg}$ body weight of OH-PCB 106 (groups IU0.05 and IU0.5, respectively) via gavage every second day from gestational day 10 to 18 , and; for lactational exposure, dams received 0.05 or $0.5 \mathrm{mg} / \mathrm{kg}$ body weight of 
Effects of perinatal exposure to OH-PCB 106 in male mice

OH-PCB 106 (groups Lac0.05 and Lac0.5, respectively) via gavage every second day from P 3 to 13. Control mice received an equivalent volume of corn oil vehicle via gavage every second day from gestational day 10 to 18 (IU-Control) or from postnatal day 3 to 13 (LacControl). These control groups did not differ on any measure of body weight and behavioral performance (Supplemental Figs. S1-4), so they were combined into a single control group. The dose of OH-PCB 106 was determined based on the previous study showing behavioral alteration in male rat offspring by OH-PCB 106 (Lesmana et al., 2014). The period of in utero exposure was determined based on the findings that brain formation begins around GD 10 (Sansom and Livesey, 2009; Di Cristo, 2007). The period of lactational exposure was determined by the findings that functional development of the cerebellum is important during postnatal days and critical period is considered around P 14 (Hashimoto and Kano, 2013; Koibuchi et al., 2003). Pups were housed with their mothers until weaning at 21 days of age. Behavioral tests were carried out when the male offspring reached at 6-7 weeks of age. Table 1 shows the number of dams and male offspring used in this study.

\section{Circadian spontaneous locomotor activity}

At 6-7 weeks of age, male offspring were individually housed in standard cages $(23.5 \times 16.5 \times 13 \mathrm{~cm})$ under normal laboratory conditions as described above. After a habituation period of three days, circadian spontaneous locomotor activity was monitored using an infrared sensor placed over each cage. Infrared beam crossings were continuously recorded and sent to an online data-acquisition system (NS-ASS01, O'hara, Tokyo, Japan). The floor of each cage was covered with sawdust and food and water were available.

\section{Open field test}

One week after monitoring circadian locomotor activity, spontaneous locomotor activity in a novel environment was assessed in an open field. The apparatus was a square

Table 1. The numbers of dams and male pups used in this study.

\begin{tabular}{lcc}
\hline Group & Dams & Pups \\
\hline Control & 6 & \\
IU-Control & 7 & 10 \\
Lac-Control & 7 & 12 \\
IU0.05 & 7 & 16 \\
IU0.5 & 4 & 22 \\
Lac0.05 & 5 & 12 \\
Lac0.5 & 5 \\
\hline
\end{tabular}

arena $(45 \times 45 \times 20 \mathrm{~cm})$ equipped with 16 surrounding infrared beams coupled to a computerized control unit (LE 8811, Panlab, S.L.U., Barcelona, Spain). Mice were placed in the center of the arena and left to freely explore for $30 \mathrm{~min}$ per test session. Travel distance was analyzed using the Acti-Track program (Panlab, S.L.U.).

\section{Rotarod test}

Three days after the open field test, mice were assessed for motor coordination and balance using a rotarod apparatus (LSI-Letica Scientific Instruments, Barcelona, Spain). After a 1-min adaptation on the rod (3 cm in diameter) at a constant speed (4 rpm), the rod was continuously accelerated from 4 to $40 \mathrm{rpm}$ over $2 \mathrm{~min}$. The latency (sec) to falling was recorded. This test was conducted by the experimenter, who was blind to the group assignment.

\section{Statistical analysis}

Data were analyzed using one-way analysis of variance (ANOVA) (rotarod test) and two-way ANOVA (circadian activity and open field test) for repeated measures followed by Tukey's honest significant difference (HSD) test. All data were the litter as the statistical unit, and expressed as the mean \pm standard error of the mean (S.E.M.), with $P$ values lower than 0.05 were considered to be significant.

\section{RESULTS}

\section{Spontaneous locomotor activity in the home cage}

First, the circadian locomotor activity of prenatally or lactationally $\mathrm{OH}-\mathrm{PCB}$ 106-exposed male offspring for $24 \mathrm{hr}$ was evaluated after a habituation period of three days. Figure 1A shows the total number of activity counts during the light and dark phases. All animals displayed increased locomotor activity in the dark phase; in particular, the activity of mice in the IU0.05 and 0.5 groups both increased remarkably during the dark phase. The twoway ANOVA revealed significant main effects of group $\left(\mathrm{F}_{(4,31)}=3.43, p<0.05\right)$, phase $\left(\mathrm{F}_{(1,31)}=506.07\right.$, $p<0.05)$, and a significant interaction of group $\times$ phase $\left(\mathrm{F}_{(4,31)}=5.39, p<0.05\right)$. Further analyses of simple main effects during each phase revealed a significant main effect of group during the dark phase $\left(\mathrm{F}_{(4,62)}=47.7, p<0.05\right)$. A post-hoc Tukey's HSD test showed that the locomotor activity of both IU groups during the dark phase was significantly higher than that of the control group $(p<0.05)$. Fig. 1B shows the number of activity counts during a 24-hr continuous session. Two-way ANOVA revealed significant main effects of group $\left(\mathrm{F}_{(4,31)}=3.43, p<0.05\right)$, time $\left(\mathrm{F}_{(23,713)}=116.25, p<0.05\right)$, and a significant interaction 

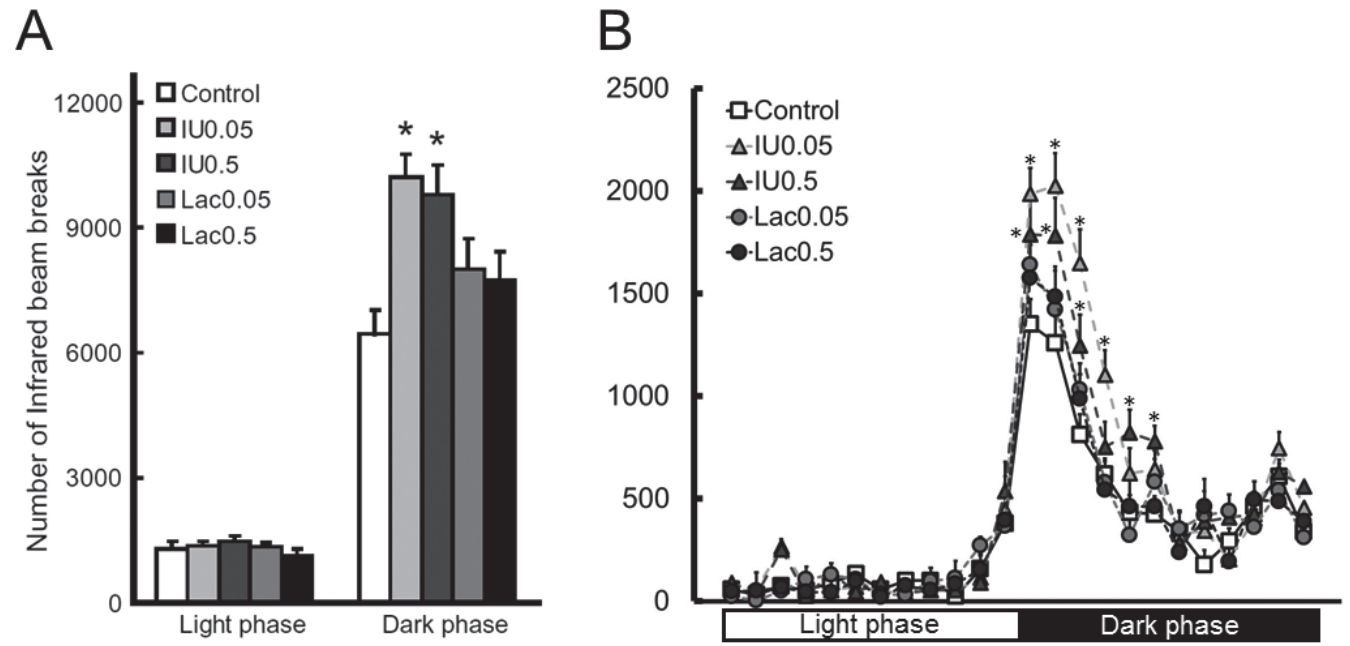

Fig. 1. Number of activity counts in the home cage (A) during the light and dark phases, and (B) during a 24-hr continuous session. Control, offspring born to dams exposed to corn oil; IU0.05 and IU0.5, offspring born to dams prenatally exposed to 0.05 or $0.5 \mathrm{mg} / \mathrm{kg}$ body weight OH-PCB 106, respectively; Lac0.05 and Lac0.5, offspring born to dams lactationally exposed to 0.05 or $0.5 \mathrm{mg} / \mathrm{kg}$ body weight OH-PCB 106, respectively. Values represent mean \pm S.E.M. and asterisks indicate significant differences from the control group $(* \mathrm{p}<0.05)$.

of group $\times$ time $\left(\mathrm{F}_{(92,713)}=2.26, p<0.05\right)$. Further analyses of simple main effects during each phase revealed that there was a significant main effect of group during the first $\left(\mathrm{F}_{(4,744)}=6.37, p<0.05\right)$, second $\left(\mathrm{F}_{(4,744)}=10.12\right.$, $p<0.05)$, third $\left(\mathrm{F}_{(4,744)}=10.26, p<0.05\right)$, fourth $\left(\mathrm{F}_{(4,744)}=5.66, p<0.05\right)$, and fifth $\left(\mathrm{F}_{(4,744)}=4.22, p<0.05\right)$ time periods of the dark phase. A post-hoc Tukey's HSD test showed that locomotor activity of the IU0.05 group was significantly higher than that of the control group during the first to fourth time periods of the dark phase $(p<0.05)$, and that of the IU0.5 group was significantly higher than that of the control group during the fifth time period of the dark phase $(p<0.05)$. Circadian rhythm itself was not different among the groups; activity phases such as the beginning of activity and the peak time of activity were not significantly different among the groups.

\section{Open field test}

Next, spontaneous locomotor activity in a novel environment was examined. Figure 2 shows the distances traveled $(\mathrm{cm})$ in the open field. Both IU groups showed an increase in travel distance during the first 10 -min block and a gradual decrease during the test time (30 min). However, neither Lac group showed a decrease in locomotor activity during the test time. Instead, mice showed an increase in distance traveled during the second

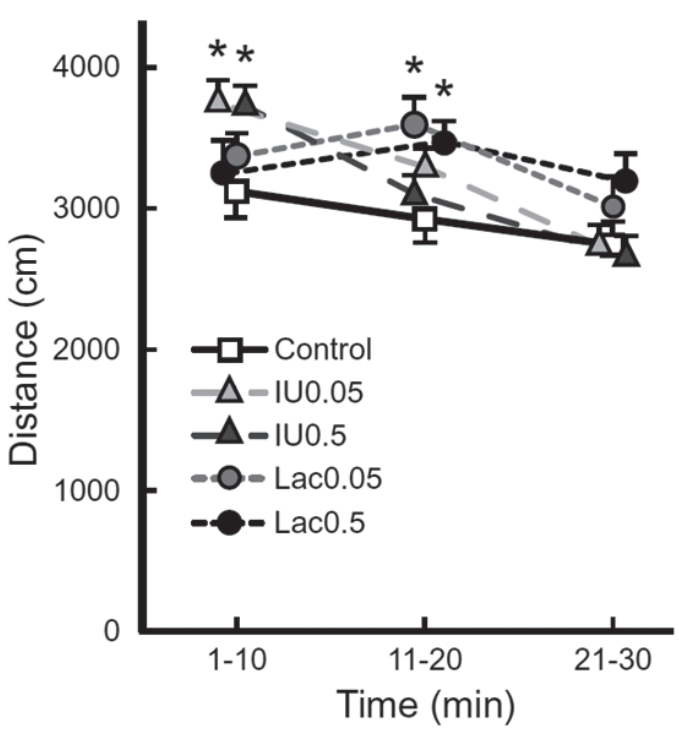

Fig. 2. Distance traveled $(\mathrm{cm})$ in the open field. Control, offspring born to dams exposed to corn oil; IU0.05 and IU0.5, offspring born to dams prenatally exposed to 0.05 or $0.5 \mathrm{mg} / \mathrm{kg}$ body weight $\mathrm{OH}-\mathrm{PCB} 106$, respectively; Lac0.05 and Lac0.5, offspring born to dams lactationally exposed to 0.05 or $0.5 \mathrm{mg} / \mathrm{kg}$ body weight OH-PCB 106, respectively. Values represent mean \pm S.E.M. and asterisks indicate significant differences from the control group $(* \mathrm{p}<0.05)$. 
Effects of perinatal exposure to OH-PCB 106 in male mice

10-min block. Two-way ANOVA revealed a significant main effect of group $\left(\mathrm{F}_{(4,31)}=3.09, p<0.05\right)$ and time $\left(\mathrm{F}_{(2,62)}=16.18, p<0.05\right)$ and a significant interaction of group $\times$ time $\left(\mathrm{F}_{(8,62)}=2.79, p<0.05\right)$. Further analyses of simple main effects during each 10-min time block showed significant main effects of group at the first $\left(\mathrm{F}_{(4,93)}=2.65, p<0.05\right)$ and second $\left(\mathrm{F}_{(4,93)}=2.59, p<\right.$ 0.05) 10-min time blocks. A post-hoc Tukey's HSD test showed that the travel distance of both IU groups was significantly longer than that of the control group during the first 10-min block $(p<0.05)$ and that of both Lac groups was significantly longer than that of the control group during the second 10-min block.

\section{Rotarod test}

Figure 3 shows the latency (sec) to falling from the rotarod. Both Lac groups performed poorly, and a oneway ANOVA showed a significant main effect of group $\left(\mathrm{F}_{(4,31)}=4.64, p<0.05\right)$. According to post hoc analysis using Tukey's HSD test, the latency of both Lac groups was significantly shorter than that of the control group $(p<0.05)$.

\section{DISCUSSION}

In this study, we investigated whether in utero or lactational OH-PCB 106 exposure affected spontaneous loco-

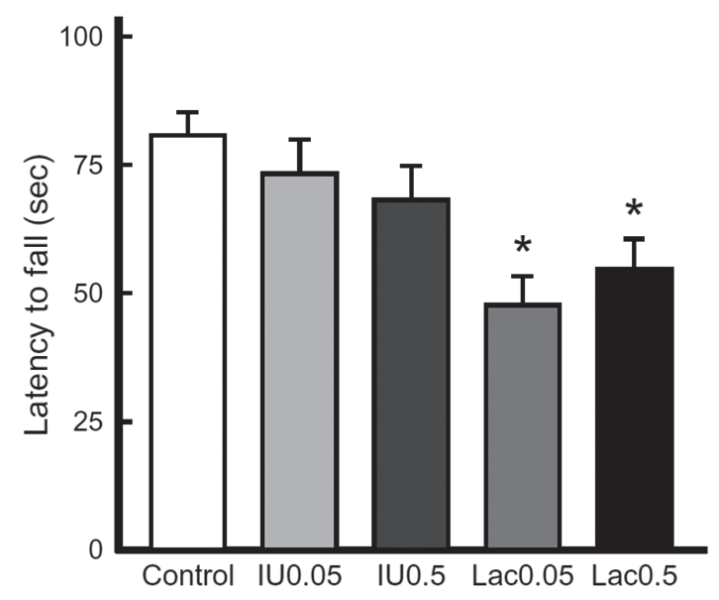

Fig. 3. The latency (sec) to falling from the rotarod. Control, offspring born to dams exposed to corn oil; IU0.05 and IU0.5, offspring born to dams prenatally exposed to 0.05 or $0.5 \mathrm{mg} / \mathrm{kg} \mathrm{OH}-\mathrm{PCB} 106$ body weight, respectively; Lac0.05 and Lac0.5, offspring born to dams lactationally exposed to 0.05 or $0.5 \mathrm{mg} / \mathrm{kg}$ body weight OH-PCB 106, respectively. Values represent mean \pm S.E.M. and asterisks indicate significant differences from the control group $(* \mathrm{p}<0.05)$. motor activity and motor coordination in young adult male mice. In utero exposure to OH-PCB 106 induced spontaneous locomotor hyperactivity in the home cage and novel environments. Lactationally OH-PCB 106-exposed groups showed spontaneous locomotor hyperactivity in the novel environment and dysfunctional motor coordination. These results indicate differential neurotoxic effects between in utero and lactational exposure to OH-PCB 106.

This study demonstrated that both in utero and lactational exposure to OH-PCB 106 affected spontaneous locomotor activity and motor coordination, but that alterations in behavior during each task were different depending on the time of exposure. Results suggest that the neurotoxic effects of OH-PCB 106 could vary according to the period of $\mathrm{OH}-\mathrm{PCB} 106$ exposure. Indeed, OHPCBs are thought to be excreted more rapidly from the body compared with parent PCBs (Malmberg et al., 2004; Soechitram et al., 2004; Quinete et al., 2014), as hydroxylated metabolites are generally more hydrophilic than parent compounds, which are lipophilic and mainly accumulate in adipose tissue. Thus, it is considered that the duration of exposure to OH-PCB 106 may be shorter than that of a parent PCB. In addition, since the development and formation of each brain region and neural circuit begins at a different time point during the perinatal period (Di Cristo, 2007; Koibuchi et al., 2003), which brain regions and neural circuits are affected by OH-PCB 106 exposure could depend on the timing of exposure.

Since OH-PCB 106 exposure with both dose induced behavioral alterations, a clear dose-response relationship was not observed in this study. Thus, lower dose of $\mathrm{OH}-$ PCB 106 exposure may induce neurotoxic effects. Concerning the dose-response relationship, parent PCBs have been reported to exhibit non-linear (i.e. U-shaped or inverted U-shaped) effects in some cases in humans and rodents (Meyer et al., 2015; Roos et al., 2013; Sugawara et al., 2006). In addition, we have found inverted U-shaped relationships for OH-PCB 106 and locomotor activities in male rat offspring (Lesmana et al., 2014). Although there were no significant differences among groups in this study, both IU and Lac higher dose exposure (0.5 mg OH-PCB $106 / \mathrm{kg}$ ) tended to less effective compared to lower dose exposure (0.05 mg OH-PCB 106/kg). Thus, it is possible that the neurotoxic effects of $\mathrm{OH}-$ PCB 106 may show inverted U-shaped relations in male mouse offspring. However, the dose-response relationship of OH-PCB 106 was not uncovered in the present study. Further investigation is needed to reveal this issue.

By analyzing circadian locomotor activity in the home cage, results show that circadian activity phases were 
not significantly different between the groups during the light or dark phases. This suggests that in utero and lactational exposure to OH-PCB 106 does not affect the brain regions involved in generating circadian activity. However, mice exposed to OH-PCB in utero, but not lactationally, had increased home cage locomotor activity during the dark phase only. This result is not consistent with our previous study that showed lactational exposure to $\mathrm{OH}$ PCB 106 increased locomotor activity throughout the day in rats (Lesmana et al., 2014). Therefore, although exposure to OH-PCB 106 may induce locomotor hyperactivity, the critical period of exposure for inducing hyperactivity may be different between species. Although differences in brain growth timescales between species may in part account for such differential responses to exposure (Semple et al., 2013), factors causing such differences have not yet been clarified. Further investigation is needed to elucidate this discrepancy.

Although the mechanisms causing hyperactivity in the present study are not clear, one possibility may be modulation of the dopaminergic system by OH-PCB 106. The dopaminergic system is considered to play an important role in spontaneous locomotor activity (Cabib et al., 2002; Viggiano et al., 2003). For instance, dopamine transporter knockout mice displayed locomotor hyperactivity and exhibited elevated extracellular dopamine levels in the striatum and nucleus accumbens (Spielewoy et al., 2000). Administration of psychostimulants such as amphetamine induced hyperactivity by increasing the release of dopamine (Rowley et al., 2012). In addition, hyperactivity in the home cage during the dark phase was correlated with an elevation in dopamine levels in the striatum (Decker et al., 2005). Perinatal and subchronic exposure to some PCB congeners and OH-PCB 106 induced alterations in the dopaminergic nervous system in rodents (Caudle et al., 2006; Faroon et al., 2000; Lee et al., 2012; Lesmana et al., 2014; Seegal et al., 2005). The results from this study, therefore, suggest that hyperactivity of mice exposed to OH-PCB 106 in utero in the home cage during the dark phase may be caused by the disruption of the dopaminergic nervous system.

Several factors can be considered regarding the target of $\mathrm{OH}-\mathrm{PCB} 106$, with one possibility being the $\mathrm{TH}$ system. This system plays important roles in the development of the dopaminergic system, including dopamine neuron differentiation and migration (Blum et al., 1999; Chen et al., 2015; Mittag et al., 2009). It is known that disruption of the TH system during the perinatal period can induce brain dysfunction (Delange, 1994; Koibuchi and Chin, 2000), and previous in vitro and in vivo studies have reported that some parent PCBs affect the $\mathrm{TH}$ system in rodents (Branchi et al., 2005; Brouwer et al., 1998; Darras, 2008; Gilbert et al., 2012; Hallgren et al., 2001; Hood et al., 2003). In addition, our previous in vitro studies demonstrated that $\mathrm{OH}-\mathrm{PCB} 106$ exposure suppressed TH-mediated transcription (Amano et al., 2010; Iwasaki et al., 2002; Miyazaki et al., 2004, 2008). Thus, the results from this study suggest that in vivo $\mathrm{OH}-\mathrm{PCB}$ 106 exposure may also affect $\mathrm{TH}$ functions. However, the present study did not examine the serum concentrations of $\mathrm{TH}$ and molecular mechanism in vivo of neurotoxic effects of OH-PCB 106 exposure on TH system. Further investigation is needed to determine whether in utero or lactational exposure to OH-PCB 106 affects serum TH levels, and molecular mechanism of OH-PCB 106 developmental neurotoxicity in vivo.

Concerning spontaneous locomotor activity in the open field, although both in utero and lactational exposure caused hyperactivity, the characteristics of the behavior were different. Both in utero groups showed a significant increase in travel distance during the first 10-min block, and then a gradual decrease during the test time (30 $\mathrm{min})$. Neither lactational group, however, showed a decrease in locomotor activity during the test time. Instead, the mice showed a significant increase in travel distance during the second 10-min block. A time-dependent decrease in travel distance is considered to reflect diminishing novelty of the test environment, namely habituating to the environment (Crawley, 2008). The results from the present study suggest that in utero exposure to $\mathrm{OH}-\mathrm{PCB} 106$ may cause novelty-induced hyperactivity in the open field, whereas lactational exposure to OH-PCB 106 may affect the ability to habituate to novel environments.

Abnormalities in emotional and cognitive functions result in aberrant behaviors in the open field, including novelty-induced hyperactivity and the lack of ability to habituate to novel environments (Belzung and Griebel, 2001; Crawley, 1985). Such aberrant behaviors may be caused by alterations to several neural circuits including the dopaminergic, serotonergic, and glutamatergic systems (Deltheil et al., 2008; Overstreet et al., 2003; Saitoh et al., 2014; Viggiano et al., 2003). However, the neurotoxic effects of perinatal OH-PCB 106 exposure on brain functions remain largely unclear. Nevertheless, previous studies have reported that exposure to perinatal PCB congeners affects emotional and learning/memory functions (Branchi et al., 2002; Curran et al., 2012; Eriksson and Fredriksson, 1998; Haave et al., 2011; Sable et al., 2006; Sugawara et al., 2006), accompanied by alterations to serotonergic and glutamatergic systems (Altmann et al., 2001; Boix and Cauli, 2012; Roegge et al., 2000; Singh et $a l ., 2013$ ) in addition to the dopaminergic system. There- 
Effects of perinatal exposure to OH-PCB 106 in male mice

fore, $\mathrm{OH}-\mathrm{PCB} 106$ exposure may have neurotoxic effects on emotional and cognitive functions through the disruption of these systems. Further investigation is needed to elucidate which brain functions and brain regions are affected by perinatal OH-PCB 106 exposure.

Mice exposed to OH-PCB lactationally demonstrated significantly poorer performance in the rotarod test than control mice. This test measures motor coordination and balance (Barlow et al., 1996), in which the cerebellum has an essential role (Carter et al., 1999). A previous in vitro study reported that $\mathrm{OH}-\mathrm{PCB} 106$ exposure suppressed the TH-dependent dendritic development of mouse cerebellar Purkinje cells (Kimura-Kuroda et al., 2007). It is known that $\mathrm{TH}$ has a critical role in cerebellar development during the postnatal period in rodents (Hashimoto and Kano, 2013; Rabie et al., 1979), and a deficiency during the perinatal period results in abnormal brain development (Dong et al., 2005; Yu et al., 2015; Amano et al., 2016). In addition, our previous studies have demonstrated that $\mathrm{OH}-\mathrm{PCB} 106$ affects the TH functions described above. Thus, the results of the present study suggest that lactational exposure to OH-PCB 106 could induce dysfunctional motor coordination and affect cerebellar development via disruption of TH function. In utero exposure, however, did not cause abnormal motor coordination. Since OH-PCBs are considered to be easily eliminated from the body, the neurotoxic effects of in utero $\mathrm{OH}-\mathrm{PCB}$ 106 exposure on cerebellar development may diminish during the postnatal period.

In conclusion, perinatal exposure to $\mathrm{OH}-\mathrm{PCB} 106$ caused several behavioral alterations in male mice. Offspring born after in utero exposure to OH-PCB 106 showed hyperactivity in the home cage and novel environments. Lactational exposure to $\mathrm{OH}-\mathrm{PCB} 106$ affected motor coordination and the ability of the mice to habituate to a novel environment.

\section{ACKNOWLEDGMENTS}

This study was supported in part by Grant-in-aid for Young Scientists (B) from the Japan Society for the Promotion of Science (to AH), and by Ministry of the Environment of Japan (EXTEND 2010) (to NK). We thank Hiroko Masuda for her technical assistance.

Conflict of interest---- The authors declare that there is no conflict of interest.

\section{REFERENCES}

Altmann, L., Mundy, W.R., Ward, T.R., Fastabend, A. and Lilienthal,
H. (2001): Developmental exposure of rats to a reconstituted PCB mixture or aroclor 1254: effects on long-term potentiation and $[3 \mathrm{H}] \mathrm{MK}-801$ binding in occipital cortex and hippocampus. Toxicol. Sci., 61, 321-330.

Amano, I., Miyazaki, W., Iwasaki, T., Shimokawa, N. and Koibuchi, N. (2010): The effect of hydroxylated polychlorinated biphenyl (OH-PCB) on thyroid hormone receptor (TR)-mediated transcription through native-thyroid hormone response element (TRE). Ind. Health, 48, 115-118.

Amano, I., Takatsuru, Y., Toya, S., Haijima, A., Iwasaki, T., Grasberger, H., Refetoff, S. and Koibuchi, N. (2016): Aberrant cerebellar development in mice lacking dual oxidase maturation factors. Thyroid, 26, 741-752.

Barlow, C., Hirotsune, S., Paylor, R., Liyanage, M., Eckhaus, M., Collins, F., Shiloh, Y., Crawley, J.N., Ried, T., Tagle, D. and Wynshaw-Boris, A. (1996): Atm-deficient mice: a paradigm of ataxia telangiectasia. Cell, 86, 159-171.

Belzung, C. and Griebel, G. (2001): Measuring normal and pathological anxiety-like behaviour in mice: a review. Behav. Brain Res., 125, 141-149.

Berger, D.F., Lombardo, J.P., Jeffers, P.M., Hunt, A.E., Bush, B., Casey, A. and Quimby, F. (2001): Hyperactivity and impulsiveness in rats fed diets supplemented with either Aroclor 1248 or PCB-contaminated St. Lawrence river fish. Behav. Brain Res., 126, 1-11.

Berghuis, S.A., Soechitram, S.D., Hitzert, M.M., Sauer, P.J. and Bos, A.F. (2013): Prenatal exposure to polychlorinated biphenyls and their hydroxylated metabolites is associated with motor development of three-month-old infants. Neurotoxicology, 38, 124-130.

Berridge, M.J., Lipp, P. and Bootman, M.D. (2000): The versatility and universality of calcium signalling. Nat. Rev. Mol. Cell Biol., 1, 11-21.

Blum, M., Weickert, C. and Carrasco, E. (1999): The weaver GIRK2 mutation leads to decreased levels of serum thyroid hormone: characterization of the effect on midbrain dopaminergic neuron survival. Exp. Neurol., 160, 413-424.

Boix, J. and Cauli, O. (2012): Alteration of serotonin system by polychlorinated biphenyls exposure. Neurochem. Int., 60, 809816.

Boix, J., Cauli, O. and Felipo, V. (2010): Developmental exposure to polychlorinated biphenyls 52,138 or 180 affects differentially learning or motor coordination in adult rats. Mechanisms involved. Neuroscience, 167, 994-1003.

Branchi, I., Alleva, E. and Costa, L.G. (2002): Effects of perinatal exposure to a polybrominated diphenyl ether (PBDE 99) on mouse neurobehavioural development. Neurotoxicology, 23, 375-384.

Branchi, I., Capone, F., Vitalone, A., Madia, F., Santucci, D., Alleva, E. and Costa, L.G. (2005): Early developmental exposure to BDE 99 or Aroclor 1254 affects neurobehavioural profile: interference from the administration route. Neurotoxicology, 26, 183192.

Breivik, K., Sweetman, A., Pacyna, J.M. and Jones, K.C. (2002): Towards a global historical emission inventory for selected PCB congeners--a mass balance approach. 1. Global production and consumption. Sci. Total Environ., 290, 181-198.

Brouwer, A., Morse, D.C., Lans, M.C., Schuur, A.G., Murk, A.J., Klasson-Wehler, E., Bergman, A. and Visser, T.J. (1998): Interactions of persistent environmental organohalogens with the thyroid hormone system: mechanisms and possible consequences for animal and human health. Toxicol. Ind. Health, 14, 59-84. 
Cabib, S., Puglisi-Allegra, S. and Ventura, R. (2002): The contribution of comparative studies in inbred strains of mice to the understanding of the hyperactive phenotype. Behav. Brain Res., 130, 103-109.

Carpenter, D.O. (1998): Polychlorinated biphenyls and human health. Int. J. Occup. Med. Environ. Health, 11, 291-303.

Carter, R.J., Lione, L.A., Humby, T., Mangiarini, L., Mahal, A., Bates, G.P., Dunnett, S.B. and Morton, A.J. (1999): Characterization of progressive motor deficits in mice transgenic for the human Huntington's disease mutation. J. Neurosci., 19, 32483257.

Caudle, W.M., Richardson, J.R., Delea, K.C., Guillot, T.S., Wang, M., Pennell, K.D. and Miller, G.W. (2006): Polychlorinated biphenyl-induced reduction of dopamine transporter expression as a precursor to Parkinson's disease-associated dopamine toxicity. Toxicol. Sci., 92, 490-499.

Chen, C., Ma, Q., Chen, X., Zhong, M., Deng, P., Zhu, G., Zhang, Y., Zhang, L., Yang, Z., Zhang, K., Guo, L., Wang, L., Yu, Z. and Zhou, Z. (2015): Thyroid hormone-Otx2 signaling is required for embryonic ventral midbrain neural stem cells differentiated into dopamine neurons. Stem Cells Dev., 24, 1751-1765.

Ciccolini, F., Collins, T.J., Sudhoelter, J., Lipp, P., Berridge, M.J. and Bootman, M.D. (2003): Local and global spontaneous calcium events regulate neurite outgrowth and onset of GABAergic phenotype during neural precursor differentiation. J. Neurosci., 23, 103-111.

Cocchi, D., Tulipano, G., Colciago, A., Sibilia, V., Pagani, F., Viganò, D., Rubino, T., Parolaro, D., Bonfanti, P., Colombo, A. and Celotti, F. (2009): Chronic treatment with polychlorinated biphenyls (PCB) during pregnancy and lactation in the rat: Part 1: Effects on somatic growth, growth hormone-axis activity and bone mass in the offspring. Toxicol. Appl. Pharmacol., 237, 127136.

Crawley, J.N. (1985): Exploratory behavior models of anxiety in mice. Neurosci. Biobehav. Rev., 9, 37-44.

Crawley, J.N. (2008): Behavioral phenotyping strategies for mutant mice. Neuron, 57, 809-818.

Curran, C.P., Altenhofen, E., Ashworth, A., Brown, A., Kamau-Cheggeh, C., Curran, M., Evans, A., Floyd, R., Fowler, J., Garber, H., Hays, B., Kraemer, S., Lang, A., Mynhier, A., Samuels, A. and Strohmaier, C. (2012): AhrdCyp1a2(-/-) mice show increased susceptibility to PCB-induced developmental neurotoxicity.. Neurotoxicology, 33, 14361442.

Darras, V.M. (2008): Endocrine disrupting polyhalogenated organic pollutants interfere with thyroid hormone signalling in the developing brain. Cerebellum, 7, 26-37.

Decker, M.J., Jones, K.A., Solomon, I.G., Keating, G.L. and Rye, D.B. (2005): Reduced extracellular dopamine and increased responsiveness to novelty: neurochemical and behavioral sequelae of intermittent hypoxia. Sleep, 28, 169-176.

Delange, F. (1994): The disorders induced by iodine deficiency. Thyroid, 4, 107-128.

Deltheil, T., Guiard, B.P., Cerdan, J., David, D.J., Tanaka, K.F., Repérant, C., Guilloux, J.P., Coudoré, F., Hen, R. and Gardier, A.M. (2008): Behavioral and serotonergic consequences of decreasing or increasing hippocampus brain-derived neurotrophic factor protein levels in mice. Neuropharmacology, 55, 1006-1014.

Di Cristo, G. (2007): Development of cortical GABAergic circuits and its implications for neurodevelopmental disorders. Clin. Genet., 72, 1-8.
Donato, F., Magoni, M., Bergonzi, R., Scarcella, C., Indelicato, A., Carasi, S. and Apostoli, P. (2006): Exposure to polychlorinated biphenyls in residents near a chemical factor in Italy: the food chain as main source of contamination. Chemosphere, 64, 15621572 .

Dong, H., Wade, M., Williams, A., Lee, A., Douglas, G.R. and Yauk, C. (2005): Molecular insight into the effects of hypothyroidism on the developing cerebellum. Biochem. Biophys. Res. Commun., 330, 1182-1193.

Eriksson, P. and Fredriksson, A. (1998): Neurotoxic effects in adult mice neonatally exposed to $3,3^{\prime} 4,4^{\prime} 5$-pentachlorobiphenyl or 2,3,3'4,4'-pentachlorobiphenyl. Changes in brain nicotinic receptors and behaviour. Environ. Toxicol. Pharmacol., 5, 17-27.

Eubig, P.A., Aguiar, A. and Schantz, S.L. (2010): Lead and PCBs as risk factors for attention deficit/hyperactivity disorder. Environ. Health Perspect., 118, 1654-1667.

Faroon, O., Jones, D. and de Rosa, C. (2000): Effects of polychlorinated biphenyls on the nervous system. Toxicol. Ind. Health, 16, 305-333.

Fängström, B., Athanasiadou, M., Grandjean, P., Weihe, P. and Bergman, A. (2002): Hydroxylated PCB metabolites and PCBs in serum from pregnant Faroese women. Environ. Health Perspect., 110, 895-899.

Ghisari, M. and Bonefeld-Jorgensen, E.C. (2005): Impact of environmental chemicals on the thyroid hormone function in pituitary rat GH3 cells. Mol. Cell Endocrinol., 244, 31-41.

Gilbert, M.E., Rovet, J., Chen, Z. and Koibuchi, N. (2012): Developmental thyroid hormone disruption: prevalence, environmental contaminants and neurodevelopmental consequences. Neurotoxicology, 33, 842-852.

Haave, M., Bernhard, A., Jellestad, F.K., Heegaard, E., Brattelid, T. and Lundebye, A.K. (2011): Long-term effects of environmentally relevant doses of $2,2^{\prime}, 4,4^{\prime}, 5,5^{\prime}$ hexachlorobiphenyl (PCB153) on neurobehavioural development, health and spontaneous behaviour in maternally exposed mice. Behav. Brain Funct., 7, 3 .

Hallgren, S., Sinjari, T., Håkansson, H. and Darnerud, P.O. (2001): Effects of polybrominated diphenyl ethers (PBDEs) and polychlorinated biphenyls (PCBs) on thyroid hormone and vitamin A levels in rats and mice. Arch. Toxicol., 75, 200-208.

Hashimoto, K. and Kano, M. (2013): Synapse elimination in the developing cerebellum. Cell Mol. Life Sci., 70, 4667-4680.

Hood, A., Allen, M.L., Liu, Y., Liu, J. and Klaassen, C.D. (2003): Induction of T(4) UDP-GT activity, serum thyroid stimulating hormone, and thyroid follicular cell proliferation in mice treated with microsomal enzyme inducers. Toxicol. Appl. Pharmacol., 188, 6-13.

Iwasaki, T., Miyazaki, W., Takeshita, A., Kuroda, Y. and Koibuchi, N. (2002): Polychlorinated biphenyls suppress thyroid hormoneinduced transactivation. Biochem. Biophys. Res. Commun., 299, 384-388.

Kimura-Kuroda, J., Nagata, I. and Kuroda, Y. (2005): Hydroxylated metabolites of polychlorinated biphenyls inhibit thyroid-hormone-dependent extension of cerebellar Purkinje cell dendrites. Brain Res. Dev. Brain Res., 154, 259-263.

Kimura-Kuroda, J., Nagata, I. and Kuroda, Y. (2007): Disrupting effects of hydroxy-polychlorinated biphenyl (PCB) congeners on neuronal development of cerebellar Purkinje cells: a possible causal factor for developmental brain disorders? Chemosphere, 67, S412-420.

Koibuchi, N. (2013): The role of thyroid hormone on functional organization in the cerebellum. Cerebellum, 12, 304-306. 
Effects of perinatal exposure to OH-PCB 106 in male mice

Koibuchi, N. and Chin, W.W. (2000): Thyroid hormone action and brain development. Trends Endocrinol. Metab., 11, 123-128.

Koibuchi, N., Jingu, H., Iwasaki, T. and Chin, W.W. (2003): Current perspectives on the role of thyroid hormone in growth and development of cerebellum. Cerebellum, 2, 279-289.

Koopman-Esseboom, C., Huisman, M., Weisglas-Kuperus, N., Boersma, E.R., de Ridder, M.A., Van der Paauw, C.G., Tuinstra, L.G. and Sauer, P.J. (1994): Dioxin and PCB levels in blood and human milk in relation to living areas in The Netherlands. Chemosphere, 29, 2327-2338.

Kuriyama, S.N. and Chahoud, I. (2004): In utero exposure to lowdose 2,3',4,4',5-pentachlorobiphenyl (PCB 118) impairs male fertility and alters neurobehavior in rat offspring. Toxicology, 202, 185-197.

Kuroda, Y. (2003): Effects of endocrine disruptors on brain development -development of novel assay systems for risk assessment-. Environ. Sci., 10, 23-33.

Lee, D.W., Notter, S.A., Thiruchelvam, M., Dever, D.P., Fitzpatrick, R., Kostyniak, P.J., Cory-Slechta, D.A. and Opanashuk, L.A. (2012): Subchronic polychlorinated biphenyl (Aroclor 1254) exposure produces oxidative damage and neuronal death of ventral midbrain dopaminergic systems. Toxicol. Sci., 125, 496508.

Lesmana, R., Shimokawa, N., Takatsuru, Y., Iwasaki, T. and Koibuchi, N. (2014): Lactational exposure to hydroxylated polychlorinated biphenyl (OH-PCB 106) causes hyperactivity in male rat pups by aberrant increase in dopamine and its receptor. Environ. Toxicol., 29, 876-883.

Lombardo, J.P., Berger, D.F., Hunt, A. and Carpenter, D.O. (2015): Inhalation of Polychlorinated Biphenyls (PCB) Produces Hyperactivity in Rats. J. Toxicol. Environ. Health A, 78, 1142-1153.

Londoño, M., Shimokawa, N., Miyazaki, W., Iwasaki, T. and Koibuchi, N. (2010): Hydroxylated PCB induces Ca2+ oscillations and alterations of membrane potential in cultured cortical cells. J. Appl. Toxicol., 30, 334-342.

Malmberg, T., Hoogstraate, J., Bergman, A. and Wehler, E.K. (2004): Pharmacokinetics of two major hydroxylated polychlorinated biphenyl metabolites with specific retention in rat blood. Xenobiotica, 36, 581-589.

Meerts, I.A., Assink, Y., Cenijn, P.H., Van Den Berg, J.H., Weijers, B.M., Bergman, A., Koeman, J.H. and Brouwer, A. (2002): Placental transfer of a hydroxylated polychlorinated biphenyl and effects on fetal and maternal thyroid hormone homeostasis in the rat. Toxicol. Sci., 68, 361-371.

Meyer, A.E., Miller, M.M., Nelms Sprowles, J.L., Levine, L.R. and Sable H.J. (2015): A comparison of presynaptic and postsynaptic dopaminergic agonists on inhibitory control performance in rats perinatally exposed to PCBs. Neurotoxicol. Teratol., 50, 11-22.

Mittag, J., Friedrichsen, S., Strube, A., Heuer, H. and Bauer, K. (2009): Analysis of hypertrophic thyrotrophs in pituitaries of athyroid Pax8-/- mice. Endocrinology, 150, 4443-4449.

Miyazaki, W., Iwasaki, T., Takeshita, A., Kuroda, Y. and Koibuchi, N. (2004): Polychlorinated biphenyls suppress thyroid hormone receptor-mediated transcription through a novel mechanism. J. Biol. Chem., 279, 18195-18202.

Miyazaki, W., Iwasaki, T., Takeshita, A., Tohyama, C. and Koibuchi, N. (2008): Identification of the functional domain of thyroid hormone receptor responsible for polychlorinated biphenyl-mediated suppression of its action in vitro. Environ. Health Perspect., 116, 1231-1236.

Overstreet, D.H., Commissaris, R.C., De La Garza, R. 2nd., File, S.E., Knapp, D.J. and Seiden, L.S. (2003): Involvement of
5-HT1A receptors in animal tests of anxiety and depression: evidence from genetic models. Stress, 6, 101-110.

Park, J.S., Bergman, A., Linderholm, L., Athanasiadou, M., Kocan, A., Petrik, J., Drobna, B., Trnovec, T., Charles, M.J. and Hertz-Picciotto, I. (2008): Placental transfer of polychlorinated biphenyls, their hydroxylated metabolites and pentachlorophenol in pregnant women from eastern Slovakia. Chemosphere, 70, 1676-1684.

Pinto, B., Garritano, S.L., Cristofani, R., Ortaggi, G., Giuliano, A., Amodio-Cocchieri, R., Cirillo, T., De Giusti, M., Boccia, A. and Reali, D. (2008): Monitoring of polychlorinated biphenyl contamination and estrogenic activity in water, commercial feed and farmed seafood. Environ. Monit. Assess., 144, 445-453.

Quinete, N., Schettgen, T., Bertram, J. and Kraus, T. (2014): Occurrence and distribution of PCB metabolites in blood and their potential health effects in humans: a review. Environ. Sci. Pollut. Res. Int., 21, 11951-11972.

Rabié, A., Favre, C., Clavel, M.C. and Legrand, J. (1979): Sequential effects of thyroxine on the developing cerebellum of rats made hypothyroid by propylthiouracil. Brain Res., 161, 469479.

Roegge, C.S. and Schantz, S.L. (2006): Motor function following developmental exposure to PCBS and/or MEHG. Neurotoxicol. Teratol., 28, 260-277.

Roegge, C.S., Seo, B.W., Crofton, K.M. and Schantz, S.L. (2000): Gestational-lactational exposure to Aroclor 1254 impairs radialarm maze performance in male rats. Toxicol. Sci., 57, 121-130.

Roos, V., Rönn, M., Salihovic, S., Lind, L., van Bavel, B., Kullberg, J., Johansson, L., Ahlström, H. and Lind, P.M. (2013): Circulating levels of persistent organic pollutants in relation to visceral and subcutaneous adipose tissue by abdominal MRI. Obesity (Silver Spring), 21, 413-418.

Rowley, H.L., Kulkarni, R., Gosden, J., Brammer, R., Hackett, D. and Heal, D.J. (2012): Lisdexamfetamine and immediate release d-amfetamine - differences in pharmacokinetic/pharmacodynamic relationships revealed by striatal microdialysis in freely-moving rats with simultaneous determination of plasma drug concentrations and locomotor activity. Neuropharmacology, 63, 1064-1074.

Sable, H.J., Powers, B.E., Wang, V.C., Widholm, J.J. and Schantz, S.L. (2006): Alterations in DRH and DRL performance in rats developmentally exposed to an environmental PCB mixture. Neurotoxicol. Teratol., 28, 548-556.

Saitoh, A., Ohashi, M., Suzuki, S., Tsukagoshi, M., Sugiyama, A., Yamada, M., Oka, J., Inagaki, M. and Yamada, M. (2014): Activation of the prelimbic medial prefrontal cortex induces anxiety-like behaviors via N-Methyl-D-aspartate receptor-mediated glutamatergic neurotransmission in mice. J. Neurosci. Res., 92, 1044-1053.

Sandau, C.D., Ayotte, P., Dewailly, E., Duffe, J. and Norstrom, R.J. (2002): Pentachlorophenol and hydroxylated polychlorinated biphenyl metabolites in umbilical cord plasma of neonates from coastal populations in Québec. Environ. Health Perspect., 110, 411-417.

Sansom, S.N. and Livesey, F.J. (2009): Gradients in the brain: the control of the development of form and function in the cerebral cortex. Cold Spring Harb. Perspect. Biol., 1, a002519.

Schantz, S.L., Seo, B.W., Wong, P.W. and Pessah, I.N. (1997): Long-term effects of developmental exposure to 2,2',3,5',6-pentachlorobiphenyl (PCB 95) on locomotor activity, spatial learning and memory and brain ryanodine binding. Neurotoxicology, 18, 457-467. 


\section{A. Haijima et al.}

Schantz, S.L., Widholm, J.J. and Rice, D.C. (2003): Effects of PCB exposure on neuropsychological function in children. Environ. Health Perspect., 111, 357-576.

Seegal, R.F., Brosch, K.O. and Okoniewski, R.J. (2005): Coplanar PCB congeners increase uterine weight and frontal cortical dopamine in the developing rat: implications for developmental neurotoxicity. Toxicol. Sci., 86, 125-131.

Semple, B.D., Blomgren, K., Gimlin, K., Ferriero, D.M. and NobleHaeusslein, L.J. (2013): Brain development in rodents and humans: Identifying benchmarks of maturation and vulnerability to injury across species. Prog. Neurobiol., 106-107, 1-16.

Singh, H.J., Syeda, T.U., Kakalij, R.M., Prasad, V.V. and Diwan, P.V. (2013): Erythropoietin protects polychlorinated biphenyl (Aroclor 1254) induced neurotoxicity in mice. Eur. J. Pharmacol., 707, 54-60.

Sinjari, T. and Darnerud, P.O. (1998): Hydroxylated polychlorinated biphenyls: placental transfer and effects on thyroxine in the foetal mouse. Xenobiotica, 28, 21-30.

Soechitram, S.D., Athanasiadou, M., Hovander, L., Bergman, A. and Sauer, P.J.J. (2004): Fetal exposure to PCBs and their hydroxylated metabolites in a Dutch cohort. Environ. Health Perspect., 112, 1208e1212.

Spielewoy, C., Roubert, C., Hamon, M., Nosten-Bertrand, M., Betancur, C. and Giros, B. (2000): Behavioural disturbances associated with hyperdopaminergia in dopamine-transporter knockout mice. Behav. Pharmacol., 11, 279-290.

Stewart, P., Reihman, J., Lonky, E., Darvill, T. and Pagano, J. (2000): Prenatal PCB exposure and neonatal behavioral assessment scale (NBAS) performance. Neurotoxicol. Teratol., 22,
21-29.

Sugawara, N., Nakai, K., Nakamura, T., Ohba, T., Suzuki, K., Kameo, S., Satoh, C. and Satoh, H. (2006): Developmental and neurobehavioral effects of perinatal exposure to polychlorinated biphenyls in mice. Arch. Toxicol., 80, 286-292.

Swanson, G.M., Ratcliffe, H.E. and Fischer, L.J. (1995): Human exposure to polychlorinated biphenyls (PCBs): a critical assessment of the evidence for adverse health effects. Regul. Toxicol. Pharmacol., 21, 136-150.

Tehrani, R. and Van Aken, B. (2014): Hydroxylated polychlorinated biphenyls in the environment: sources, fate, and toxicities. Environ. Sci. Pollut. Res. Int., 21, 6334-6345.

Viggiano, D., Ruocco, L.A. and Sadile, A.G. (2003): Dopamine phenotype and behaviour in animal models: in relation to attention deficit hyperactivity disorder. Neurosci. Biobehav. Rev., 27, 623-637.

Winneke, G. (2011): Developmental aspects of environmental neurotoxicology: lessons from lead and polychlorinated biphenyls. J. Neurol. Sci., 308, 9-15.

Winneke, G., Walkowiak, J. and Lilienthal, H. (2002) PCB-induced neurodevelopmental toxicity in human infants and its potential mediation by endocrine dysfunction. Toxicology, 181-182, 161165.

Yu, L., Iwasaki, T., Xu, M., Lesmana, R., Xiong, Y., Shimokawa, N., Chin, W.W. and Koibuchi, N. (2015): Aberrant cerebellar development of transgenic mice expressing dominant-negative thyroid hormone receptor in cerebellar Purkinje cells. Endocrinology, 156, 1565-1576. 